\title{
Cathelicidins: family of antimicrobial peptides. A review
}

\author{
Ewa M. Kościuczuk • Paweł Lisowski · Justyna Jarczak • \\ Nina Strzałkowska • Artur Jóźwik • Jarosław Horbańczuk • \\ Józef Krzyżewski $\cdot$ Lech Zwierzchowski $\cdot$ Emilia Bagnicka
}

Received: 1 January 2012/ Accepted: 1 October 2012/Published online: 14 October 2012

(C) The Author(s) 2012. This article is published with open access at Springerlink.com

\begin{abstract}
Cathelicidins are small, cationic, antimicrobial peptides found in humans and other species, including farm animals (cattle, horses, pigs, sheep, goats, chickens, rabbits and in some species of fish). These proteolytically activated peptides are part of the innate immune system of many vertebrates. These peptides show a broad spectrum of antimicrobial activity against bacteria, enveloped viruses and fungi. Apart from exerting direct antimicrobial effects, cathelicidins can also trigger specific defense responses in the host. Their roles in various pathophysiological conditions have been studied in mice and humans, but there are limited information about their expression sites and activities in livestock. The aim of the present review is to summarize current information about these antimicrobial peptides in farm animals, highlighting peptide expression sites, activities, and future applications for human and veterinary medicine.
\end{abstract}

Keywords AMP - Cathelicidin - Vertebrates - Human . Farm animals $\cdot$ Activity $\cdot$ Expression

\section{Introduction}

The antimicrobial peptides are a conserved component of the innate immune response in all organisms, including plants, animals and humans. Cathelicidins, together with defensins belong to the large group of cationic peptides with amphipathic properties and represent the main part of the

E. M. Kościuczuk · P. Lisowski · J. Jarczak · N. Strzałkowska · A. Jóźwik · J. Horbańczuk · J. Krzyżewski · L. Zwierzchowski · E. Bagnicka $(\bowtie)$

Institute of Genetics and Animal Breeding in Jastrzębiec, Polish Academy of Sciences, 05-552 Magdalenka, Poland

e-mail: e.bagnicka@ighz.pl immune system in many vertebrates, including humans and farm animals. A lot of antimicrobial peptides (AMPs) are stored in neutrophil and macrophage granules. They are part of the oxygen-independent activity against pathogens [1]. The existence of the family of antimicrobial peptides named cathelicidins was established based on the presence of a conserved cathelin domain. The first cathelicidin, cecropin, was isolated in 1980 from tissues of the Hyalophora cecropia moth after a 10 year study on insect immunity [2]. Another member of the cathelicidins family, magainin, was isolated in 1987 by Zasloff from the skin of the Xenopus leavis frog [3]. The first mammalian cathelicidins seemed to be bactenecins isolated in the late 1980s from bovine neutrophils. These cathelicidins were named Bac5 and 7 [4]. The porcine cecropin P1, isolated in the late 1980s is numbered in the cathelicidin family as well [5]. However, some authors state that the first mammalian described cathelicidin was rabbit CAP18 [6]. Till now, several cathelicidins have been identified in: cattle [4], buffalo [7] horse [8], pig [9], sheep [10], goat [11], deer [12], chicken [13] and some species of fish [14, 15], while only single peptides have been found in humans [16], rhesus monkeys [17], mice [18], rats [19], and guinea pigs [20]. Recently, a cathelicidin was also isolated from the snake Bungarus fasciatus [21].

The peptide family named "cathelicidins" with a common proregion (cathelin domain) were first identified in mammals in bone marrow myeloid cells [1, 22]. Therefore they are also named "myeloid antimicrobial peptides" (MAP). Cathelicidins are a group of antimicrobial peptides, varying in amino acid (a.a) sequence, structure and size. They are stored in the secretory granules of neutrophils and macrophages and can be released extracellularly upon leukocyte activation. Then, their expression was also found in non-myeolid cells for example in epithelial cells [22-24]. Cathelicidins, containing two functional domains, 
owe their name to the presence of the region with very high homology to cathelin - the cathepsin L inhibitor, at their N-terminal. The "cathelin" domain shows very high interspecies homology in cathelin basic aa sequence, while the antimicrobial domain located at $\mathrm{C}$-terminus shows high diversity, both interspecies and intraspecies [1, 22-24].

The aim of this review is to summarize information about cathelicidins with regards to farm animals in order to provide an overview of the expression sites, activities and future application for human and veterinary medicine of these antimicrobial peptides.

\section{Diversity of cathelicidins}

About 30 cathelicidin family members (Table 1 ) have been identified in mammalian species. Nevertheless, only single cathelicidins have been found in humans, rhesus monkeys, mice, rats, and guinea pigs. These cathelicidins are named LL-37, RL-37, mCRAMP, rCRAMP and CAP11, respectively [14, 16-20, 24-27]. Three cathelicidins were identified in horses (Equus caballus cathelicidin eCATH-1, -2 and -3) [8]. Furthermore, peptides similar to cathelicidins were described in pigs (Sus scrofa domestica cathelicidin PMAP37, 36 and 23, PG1, 2, 3, 4 and 5, PR39, and PF-1, -2) [28-35], cattle (Bos taurus cathelicidin BMAP27, 28 and 34, Bac5 and 7, indolicidin, and bactenecin-1) [36-39], buffalo (Buballus bubalis cathelicidin-4, myeloid cathelicidin) [7], deer (Cervus elaphus hispanicus cathelicidin, bactenecin) [12], sheep (Ovis avies cathelicidin SMAP29 and 34, OaBac5, 6, 7.5, 11) [40-42], goat (Capra hircus cathelicidin BAC5, BAC7.5, MAP34A and B, MAP28, ChBac3.4) [11, 43], chicken (Gallus gallus domesticus cathelicidin CATHL1, 2/CMAP27, 3 and Cathelicidin-B1) [13], Atlantic salmon (Salmo salar cathelicidin, asCath1 and 2) [44] and Rainbow trout (Oncorhynchus mykiss cathelicidin, rtCath1 and 2) [44]. Another fish, Atlantic hagfish (Myxine glutinosa) genome contains three cathelicidin-like sequences (HFIAP-1, -2, and -3) [15]. Moreover, two sheep genes: OaDodeA and OaDodeB encoded identical dodecapeptides named Cathelicidin-1 [40]

Cathelicidins are stored in neutrophil granules as inactive precursors (prepropeptides). They are released as mature peptides when required, after being cleaved by neutrophil elastase [45]. The $\mathrm{N}$-terminal signal sequence and proregion (cathelin) are highly conserved among species and different peptides, whereas the $\mathrm{C}$-terminal domain, encoding the mature peptide, shows substantial heterogeneity (Fig. 1) $[22,24]$. The C-terminal domains in some cathelicidin peptides are $\alpha$-helical, in others $\beta$-hairpin, and in some peptides they are proline/arginine rich. The mature peptide ranges in size from 12 to 80 or more aa residues [22]. The cathelicidin family consists of five distinct groups of peptides [24]. They comprise: (1) cyclic dodecapeptides with one disulfide bond, (2) porcine protegrins with two disulfide bonds, (3) peptides with $\alpha$-helical structure such as bovine BMAP-27, -28 and -34 , ovine SMAP-29 and -34 , porcine PMAP-23, -36 and -37 , human hCAP18 and the three known equine cathelicidins, (4) peptides containing a high number of tryptophan residues such as indolicidin and peptides containing a high number of proline and arginine residues, and (5) short molecules arranged in tandem repeats such as bactenecins (bovine Bac5 and 7, ovine OaBac5 and 7.5 as well as porcine PR-39 and prophenins) $[24,25,46]$. In the bovine bactenecin, three tandem repeats of a tetradecamer composed of several Pro-Arg-Pro triplets were found. Between triplets, a single hydrophobic aa residue occurs. Three repeats of the decamer FPPPNFPGPR were also found in pig prophenins [47].

All cathelicidins are encoded by genes consisting of four exons. The first exon covers a sequence encoding the signal peptide (part pre-) of 29-30 aa residues in size, while exons 2 and 3 encode the cathelin domain (part pro-) of 99-114 aa. Exon 4 encodes the mature peptide, with the antimicrobial domain consisting of 12-100 aa. Till now, on sheep, cow, pig and chicken chromosomes, all cathelicidin genes were found to form clusters $[13,55,56]$. Cathelicidin genes were localized on chromosome 13 in pig, chromosome 19 in sheep ( 8 genes), and in chickens on chromosome $2 p$ at the proximal end as a dense cluster within a $7.5-\mathrm{kb}$ ( 3 genes) $[13,31,40]$. In cattle, more than 10 cathelicidin genes were located in the same region on chromosome 22q24 [36]. In human and mouse genome cathelicidin genes were localized on chromosomes 3 and 9 , respectively [31].

Phylogenetic analysis demonstrated that genes encoding chicken cathelicidins and mammalian neutrophilic granule peptides are probably descendants from a single, remotely related gene, evolved prior to the separation of birds from mammals. However, it is supposed that genes encoding other "classic" mammalian cathelicidins (cathelicidins with high homology in cathelin domain) may have been duplicated from the ancestral neutrophilic granule peptide gene after mammals and birds drifted apart [13].

\section{Human cathelicidin}

Despite the existence of a great amount of beta defensin (hBD) genes in human genome reviewed in [57,58], there is only one cathelicidin gene $(C A M P)$ identified in humans. CAMP encodes the peptide LL-37 which begins with two leucine residues at its $\mathrm{N}$-terminus, and is 37 aa residues long, with a molecular weight of $18 \mathrm{kDa}$ [31]. It is also known as hCAP-18, FALL-39 or CAMP-human cationic antimicrobial peptide. LL-37 is expressed in various cells and tissues such as circulating neutrophils and myeloid bone marrow 


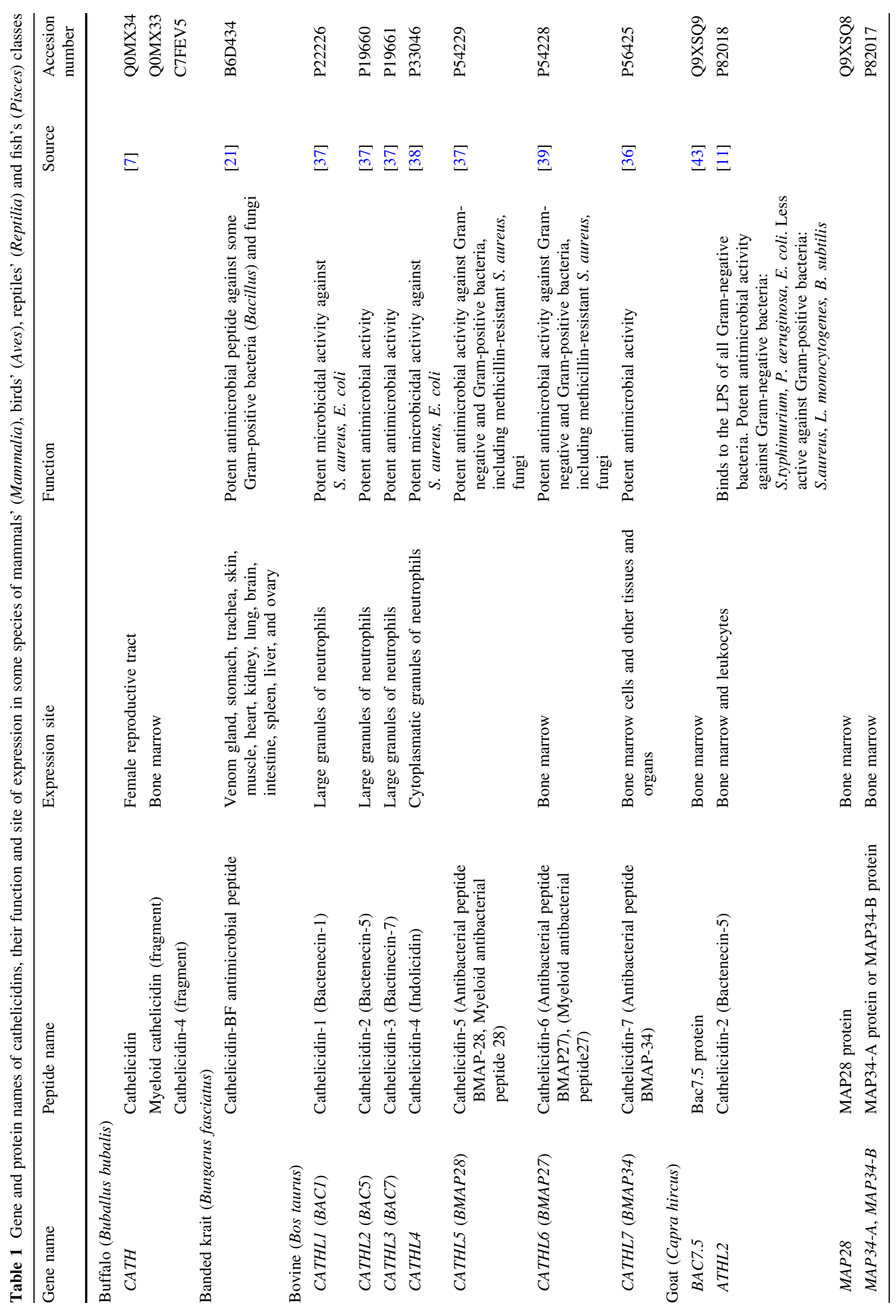




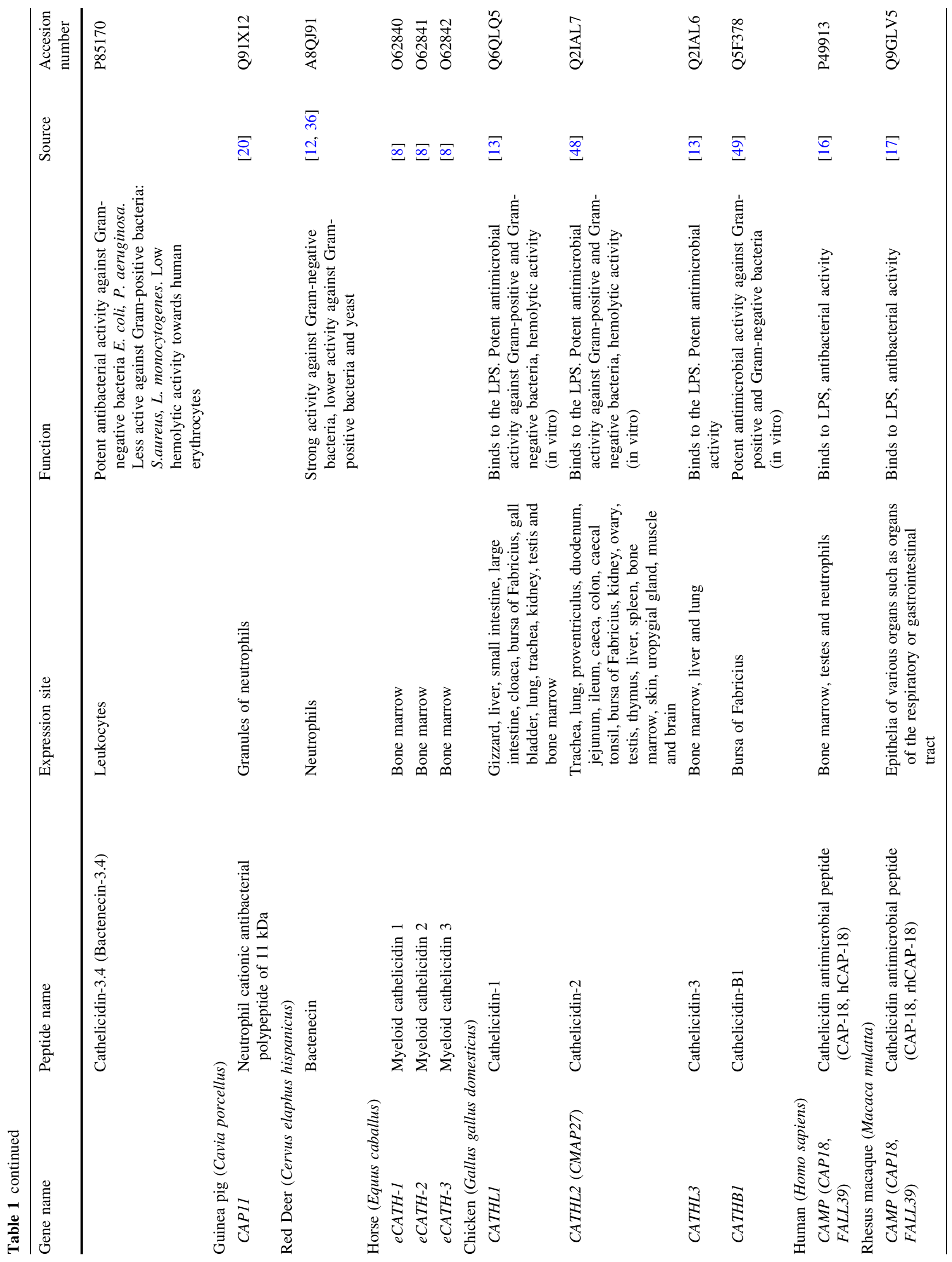




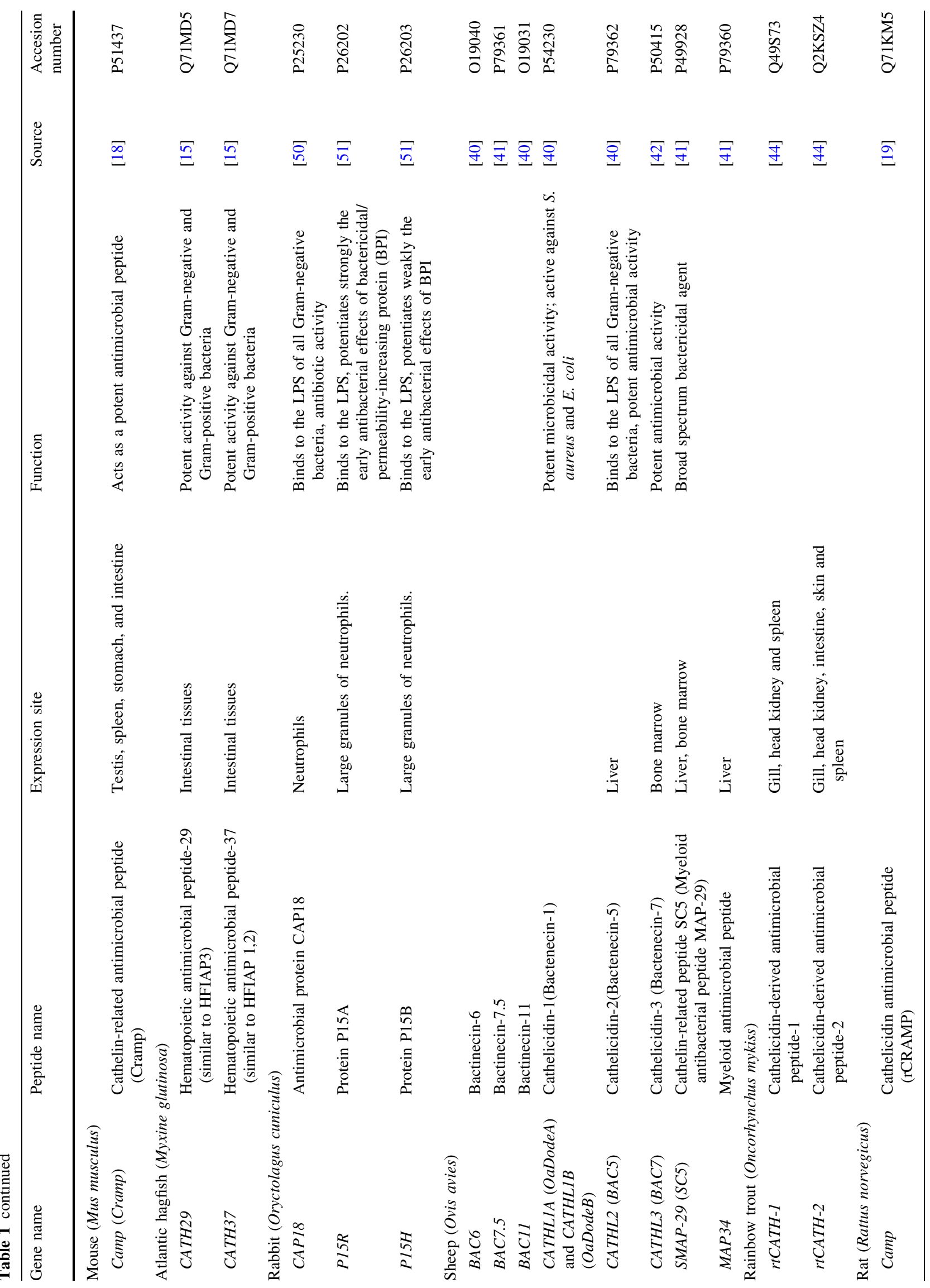




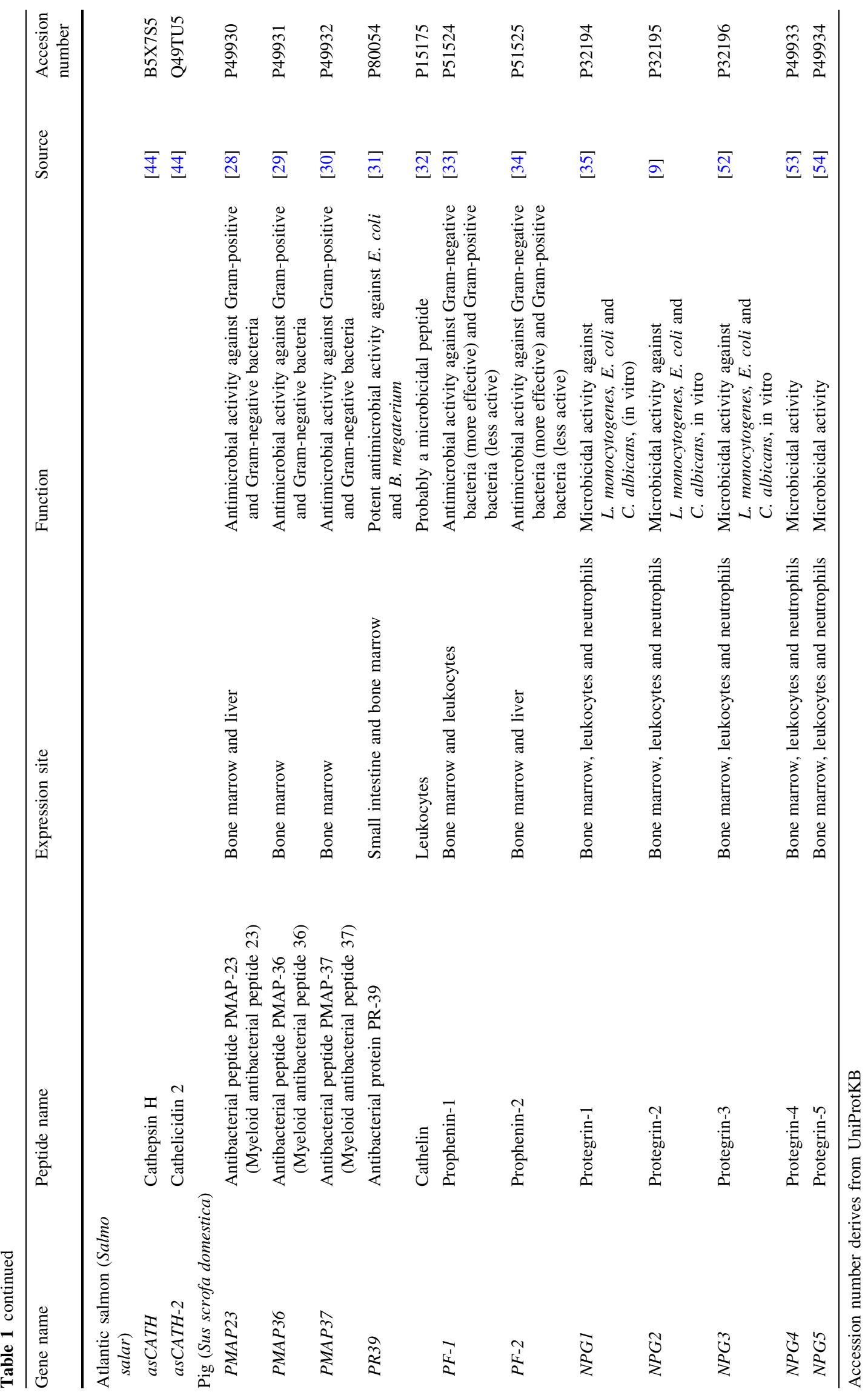



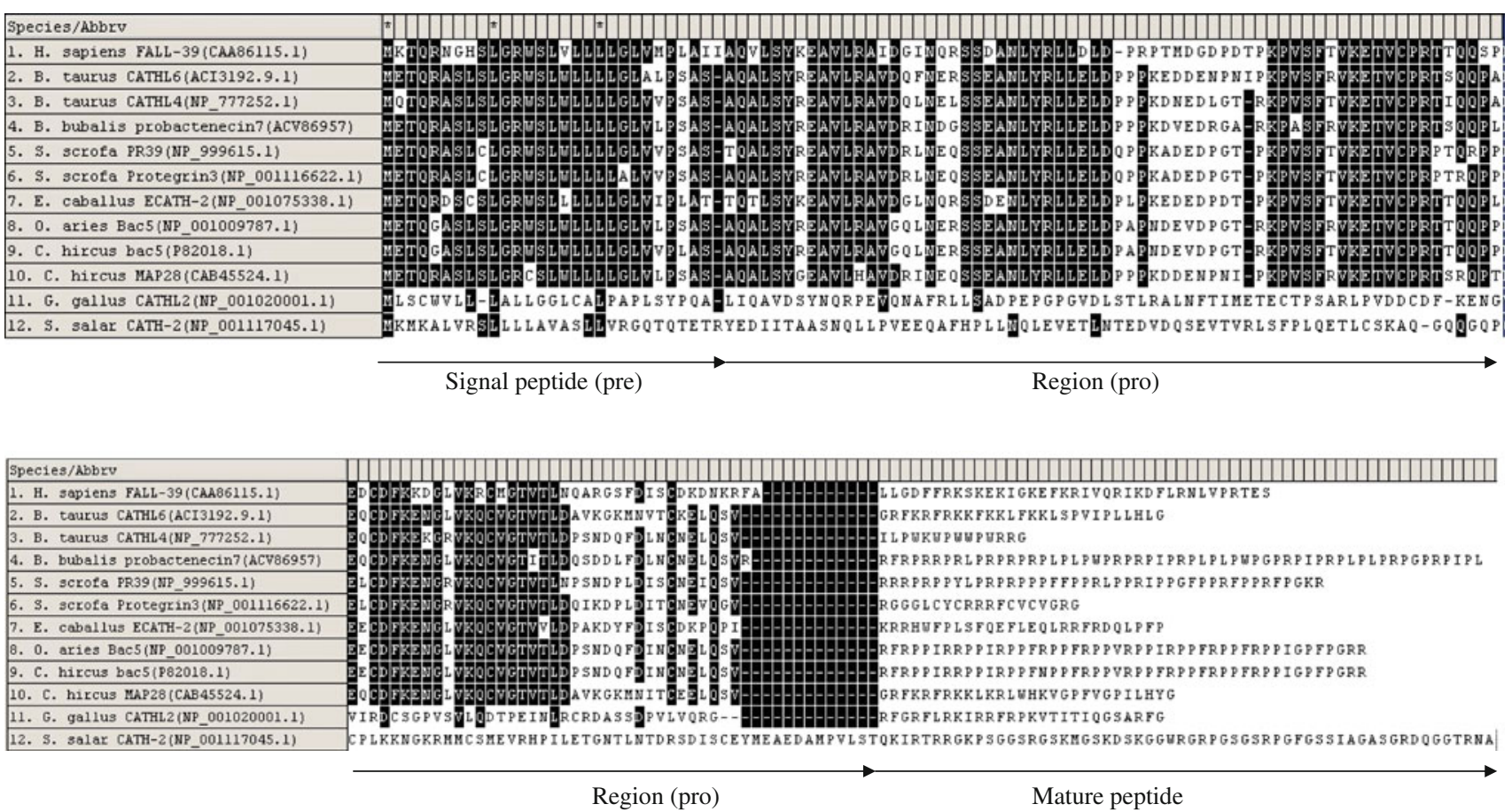

Fig. 1 Alignment of amino acid sequences of vertebrate's cathelicidins. In the left column is shown: species name, name of cathelicidin with accession no. (GenBank). Conserved site with at least $60 \%$ level of sequence identity are marked

cells, epithelial cells of the skin, and is also expressed in the gastrointestinal tract, as well as in the epididymis and lungs. Expression was also detected in squamous epithelium of the mouth, tongue, esophagus and in the colonic and bronchial mucosal epithelium [59, 60]. Moreover, production of LL-37 in macrophages is stimulated by vitamin D released by sunlight through the skin. Probably the sun baths, recommended for years for overcoming tuberculosis, increase the ability of LL-37 to kill intracellular Mycobacterium tuberculosis [61]. Transcripts of $C A M P$ gene were isolated from the lung, genitourinary tract, skin keratinocytes in inflammatory disorders, as well as from B cells, T cells, natural killer cells, monocytes, and macrophages [62]. Expression of LL-37 could be constitutive or inducible by microbial, inflammatory, and developmental stimulation. Nevertheless, the knowledge of molecular mechanisms of gene regulation is still very limited [24]. A few potential binding sites for transcription factors which probably regulate $C A M P$ gene expression were found in the human cathelicidin gene [63]. Human cathelicidin acts in the promotion of wound healing, as direct and indirect antimicrobial factors and can also modulate the adaptive immunity [64].

\section{Bovine cathelicidins}

The first bovine cathelicidins isolated from neutrophils were bactenecins 5 and 7; abbreviated as Bac5 and Bac7. The term bactenecin was created from two words: "bacterium" and the Latin word "necare" that means to kill. These peptides consist of 43 and 60 aa residues, respectively, with a different, polycationic aa sequence, but both characterized by a repeated proline motif [4]. These proline-rich antimicrobial peptides have been reported to kill bacteria without significant membrane lysis. These peptides generally show higher selectivity for Gram-negative than for Gram-positive bacteria [65]. The bactenecin expressed by bovine neutrophils (Bac5) has a $\beta$-hairpin structure with four arginine residues and one intramolecular disulfide bond. The homodimeric form of bactenecin shows higher antibacterial activity with less sensitivity to salt concentration than the monomer. Both the mono- and dimeric forms of bactenecins kill Staphyloccocus aureus at concentrations of $8-16 \mu \mathrm{M}$ within 10-30 min. The differences in the structure of peptide forms cause differences in their mode of action. The homodimeric bactenecins form pores in the pathogen's membrane to disrupt the cells, whereas the targets of monomeric peptide are intracellular organelles. As a result, this peptide inhibits some functions such as synthesis of cell wall, proteins or nucleic acids [66]. The cDNA encoding Bac5 clone was used to prove that dodecapeptide bactenecins and other structurally unrelated antimicrobial peptides of the bovine, despite their diversity, are closely related since their transcripts showed a high degree of nucleotide sequence similarity [22,67].

The bovine BMAP-27 and BMAP-28 (bovine myeloid antimicrobial peptides of 27 and 28 aa residues, 
respectively) contain $\alpha$-helical $\mathrm{C}$-terminus with structural attributes of antimicrobial activity. Owing to its direct antimicrobial activity and modulating the inflammatory response, BMAP-28 probably supports the host defense. At low concentrations in vitro, bovine BMAP-28 not only kills bacteria and fungi, but is also toxic for mammalian tumor cells, inducing their apoptosis [39, 68]. Moreover, this AMP shows cytotoxic activity against other mammalian cells. It was also demonstrated that BMAP 28 induces mitochondrial permeability forming transition pores (MPTP) resulting in the release of cytochrome c [69]. These peptides showed high effectiveness against pathogens in mastitic bovine milk and low efficiency in milk from healthy cows. BMAPs may also activate the immune response by stimulating the expression of tumor necrosis factor alpha (TNF- $\alpha)$ in bovine mammary epithelial cells [65].

Another bovine cathelicidin is indolicidin. It is a tryptophan-rich peptide of 13 aa (ILPWKWPWWPWRR$\mathrm{NH} 2$ ), purified from the cytoplasmic granules of neutrophils [38]. Moreover, Del Sal et al. [70] reported that this peptide is synthesized in bone marrow cells as 144 aa-long precursor. Indolicidin shows activity against different species of pathogenic fungi like Candida albicans, Cryptococcus neoformans, bacteria-S. aureus, and E. coli [38, 71]. This AMP exhibits a destructive effect on intracellular targets, such as bacterial DNA and RNA [65, 72] and it is capable of inducing an autophagic cell death in the protozoan pathogen Leishmania donovani [73], as well as killing the trophozoites_Giardia lam [74].

\section{Porcine cathelicidins}

Until now, five small (16-18 aa residues) cathelicidins named protegrins, with a $\beta$-hairpin structure stabilized by two intramolecular disulfide bonds between cysteines, were found in porcine bone marrow and neutrophils. Protegrins display limited sequence similarity to certain defensins and tachyplesins [75]. They have antimicrobial activity against bacteria, especially Gram-negative, fungi, and some enveloped viruses when used at concentrations of $1-5 \mu \mathrm{g} / \mathrm{ml}[9,76,77]$. Protegrin-1 (PG-1; 18 aa), consisting of 6 arginine residues, has antiparallel $\beta$-sheet structure, protegrin-2 is two aa residues shorter and has one less positive charge than in PG-1. Protegrin 3 has glycine instead of arginine at position 4 which also causes one less positive charge than PG-1. PG-4 has phenylalanine instead of valine at position 14 and this substitution caused the difference in the $\beta$-turn. This difference makes PG-4 less polar and less positively charged than other peptides. The fifth porcine protegrin-PG-5 has a substitution proline-arginine at position 10 and one less positive charge than PG-1 [78].
The gene structures of three other porcine cathelicidins have been characterized by Gudmundsson et al. and Zhao et al. [31, 34, 54]. The signal sequence of 29 residues and the first 37 residues of the cathelin propart are contained in the first exon. Exons 2 and 3 contain cathelin information, and the C-terminal domain, encoding the mature peptide PR-39 extended by three residues. PR-39 has multiple activities contributing to the innate defense of pigs. It is a proline-arginine-rich antibacterial peptide that was isolated originally from the porcine small intestine, and subsequently localized in neutrophils. PR-39 enters cells without membrane lysis, and after a short lag is capable of killing bacteria by inhibiting bacterial messenger RNA translation and DNA synthesis [79]. It was also been reported that PR-39 modulates production of proteoglycans in wound healing, to promote leukocyte chemotaxis, to interact with sarcoma homology 3 domain (SH3) of different proteins, and to inhibit superoxide production by neutrophils [79]. Increased expressions of PR-39 and protegrins in porcine bone marrow progenitor cells have been observed following cell activation with bacteria or purified lipopolysaccharides (LPS) [80].

Prophenin-1 (PF-1), the peptide with a molecular mass of 8,683 $\mathrm{Da}$ and 79 aa residues (42 prolines and 15 phenylalanines), was isolated from pig leukocytes. Three perfect and three nearly perfect repeats of a decamer, FPPPNFPGPR were found in Prophenin-1 N-terminal. Prophenin-2 (PF-2), with 97 aa residues, stored in secondary granules of neutrophils, is expressed in immature myeloid cells. Both peptides in vitro show more activity against $E$. coli, than against Listeria monocytogenes (Gram-positive bacteria) [47, 81].

\section{Caprine and ovine cathelicidins}

There are not many studies describing cathelicidins in sheep and goats. Until now, at least eight cathelin-associated peptides, were identified in sheep, including cyclic dodecapeptide, SMAP29 and Bac5, 6, and 7.5, but little is known about their antimicrobial properties [11, 43]. Four of eight cathelicidin genes encode the proline- and arginine-rich peptides named OaBac5, 6, 7.5 and 11 [40], while SMAP29 is an $\alpha$-helical peptide [43].

In goats, a peptide named ChBac5, with almost exclusively X-P-P-Y repeats, was identified and Bac7.5 as well. Shamova et al. [11] showed that Bac5 peptides from sheep and goats bind to bacterial lipopolysaccharides (LPS), a glycolipid present in the outer membrane of all Gramnegative bacteria, and Bac5 kills them at concentrations of $\mathrm{NaCl}$ similar to those found in extracellular fluids. Both cathelicidins show high activity against all microbes studied at a low salt concentration, whereas at a high salt 
concentration $(100 \mathrm{mM} \mathrm{NaCl})$ these peptides are still active against Gram-negative bacteria (E. coli, Bacillus subtilis and Pseudomonas aeruginosa), but have no activity against $S$. aureus, and C. albicans. Anderson et al. [43] found that SMAP29 and other ovine cathelicidins: OaBac5mini and OaBac7.5mini showed activity against Gram-negative, Gram-positive bacteria as well as C. albicans at minimum inhibitory concentration (MIC) between 0.125 and $64 \mu \mathrm{g} / \mathrm{ml}$, depending on the species of the microorganism. The study of Shamova et al. [82] identified in goat leukocytes, the proline-rich bactenecin-ChBac3.4 (approximate mass $3.4 \mathrm{kDa}$ ), which had over $50 \%$ identity to caprine, ovine and bovine Bac5 peptides. This cathelicidin has a high ability to damage microbial membranes (E. coli, P. aeruginosa and L. monocytogenes but with reduced efficacy against $S$. aureus, $C$. albicans), especially at a low salt concentration (10 $\mathrm{mM}$ phosphate buffer).

\section{Chicken cathelicidins}

Initially, there were three cathelicidins found in chickens (fowlicidin-1, -2 and -3, also known as chCATH-1, -2 and -3). Then, chCATH-B1 with an antibacterial activity has been discovered [83]. Fowlicidins show activity against Gram-negative and Gram-positive bacteria, including antibiotic-resistant strains. The activity of fowlicidins' MIC varied between 0.4 and $2.0 \mu \mathrm{M}$ for most strains, and activity did not depend on salt concentration [13]. The expression of these peptides was identified first in the bursa Fabricius. [84] The chicken cathelicidin B1 (chCATH-B1) in particular, is expressed exclusively in bursal epithelial cells. The C-terminus (cathelin region) of chCATH-B1 has less homology to the mammalian cathelicidins than that of chCATH-1, -2 , and -3 , [13, 48]. Van Dijk et al. [48] identified in chicken bone marrow cells the peptide CMAP27 (chicken myeloid antimicrobial peptide 27), that may play a role in chicken innate defense. It appeared to be similar to bovine myeloid antimicrobial peptides (BMAP-27, BMAP-28, BMAP-34).

\section{Horse cathelicidins}

Till now, only three cathelicidins have been identified, and those found (discovered) by Scocchi and co-workers [8] are stored in equine neutrophils. The mature peptides were found in inflammation sites, thus the processing of these propeptides probably takes place during neutrophil activation. A broad spectrum of antimicrobial activity was demonstrated for eCATH-1 and eCATH-3, while the equine cathelicidin, eCATH-2 had antibacterial activity restricted to E. coli, S. aureus. Furthermore, eCATH-3 showed potent activity against some fungi like
C. neoformans and Rhodotorula rubra, but its activity depends on the salt concentration being strongly inhibited at the physiological salt concentration $[8,85]$.

\section{Fish cathelicidins}

Several antimicrobial peptides, similar to mammalian cathelicidins, have been identified in fish [15, 44]. The cathelicidin found in Rainbow trout (Oncorhynchus mykiss) was the first identified in vertebrates outside the mammalian species [25]. The properties of fish cathelicidins have not been yet studied and there is limited information as to whether they function as a part of the immune system of fish. Atlantic cod (Gadus morhua) was found to have at least three cathelicidin genes. Two of them show difference in the $5^{\prime}$-region (N-terminal peptide region). The mature peptides of Atlantic cod contain mainly arginine, glycine and serine residues, therefore they form a novel class of peptides [86]. Cathelicidin genes in Arctic char (Salvelinus alpinus) and Brook trout (Salvelinus fontinalis) have an exon deletion in the cathelin coding region, which may result in the deletion of the predicted loop 2 of the cathelin region and its adjacent beta-strands [86]. Infection of Arctic char and Atlantic cod with pathogenic bacteria led to an increased expression of the cathelicidins hence, these peptides may play an important role in fish immunity [87].

Both Rainbow trout (Oncorhynchus mykiss) and Atlantic salmon (Salmo salar) have two cathelicidin genes each (named rtCath 1 and 2 and asCath 1 and 2, respectively). The inducible expression of cathelicidin 1 (rtCath1) was shown only after infection, while the constitutive expression of rtCath2 in many tissues was found in rainbow trout. The expression of rtCath2, however, was further upregulated after bacterial infection. The in vitro studies strongly suggest antibacterial activities of rtCath 1 and 2 [44]. The mature rainbow trout cathelicidins are 66-a.a long and contain 6 proline residues which form PGGGS repeats. The mature peptides of cathelicidins found in hagfish (HFIAP-1, 2 and 3) are alpha-helical peptides with a potent activity against Gram-negative and Gram-positive bacteria. Their conserved cathelin region contains four cysteine residues like in trout, chickens and many mammalian cathelicidins [25].

The presence of cathelicidin family members in some species of fish could mean that cathelicidin ancestors subsisted over 300 million years ago [56].

\section{Mechanisms of action against pathogens and other functions}

The majority of antimicrobial peptides belonging to a large class of cationic peptides, are amphophilic. This property is 
needed to permeate the membranes of a pathogen. The electrostatic interaction between the cationic peptide and negatively charged membrane of bacteria is probably due to the presence of its amphophilic/amphipatic properties. The hydrophilic region causes the correct alignment of the peptide on a pathogen membrane [88, 89].

The general rule of the mechanism triggering cathelicidin action, like that of other antimicrobial peptides, involves the disintegration (damaging and puncturing) of cell membranes of organisms toward which the peptide is active. Cathelicidins do not act on healthy host cell membrane. Interaction of cationic peptides and negatively charged lipid membranes of microorganisms enable their accurate, parallel adhesion and anchoring, and neutralizing the membrane charge [77]. Changing of the secondary and tertiary structure of the peptide changes its perpendicular orientation, thus embedding in the lipid bilayer and creating transmembrane pores. In its action against Gram-negative bacteria, the peptide can move across the outer membrane, and after passing the layer of peptidoglycan, crosses the inner membrane into the cytoplasm of the bacterial cell [90, 91]. Currently, several mechanisms of peptide penetration across the cytoplasmatic membrane are known. One of them is called the "barrel stave" mechanism, based on the growing of peptides in the form of barrel staves, of which the hydrophilic inner surface creates a gap [92]. Another mechanism was named the "connecting channels", when peptides combine with the cytoplasmic membrane and create clusters which penetrate into the interior of the cell by creating gaps [93]. It should be noted that cathelicidins, beyond the mechanisms of membrane binding, can also activate the extracellular factors that induce autolysing phospholipase A2 [94]. Porcine cathelicidins PR-39, indolicidin and synthetic peptide PR-26 were shown to inhibit protein synthesis and to induce the degradation of certain proteins needed for DNA replication of the pathogen [92]. The fungicidal activity of one bovine cathelicidin, indolicidin, involves disruption of cell membranes via direct interaction with the lipid bilayers in a salt-dependent and energy-independent manner [95]. Indolicidin can bind DNA with the sequence-preference, which may contribute to indolicidin antimicrobial action and can also inhibit topoisomerase 1, which cuts one strand of double-stranded DNA, relaxing and re-annealing the strands $[96,97]$.

Some actions of cathelicidins are mediated though their interaction with other cells which are the important part of innate immune system, like monocytes, dendritic cells, $\mathrm{T}$ cells and epithelial cells [98]. The susceptibility to bacterial infections of animals and humans with lowered expression of antimicrobial peptides shows their crucial role in the immune response. For this reason, there is a growing body of evidence suggesting that the immunomodulatory properties of the antimicrobial peptides-defensins and cathelicidins-might be used for the development of novel therapeutic agents [57, 98].

The fungicidal activity of some bovine and porcine cathelicidins was proved in the in vitro study. SMAP-29, BMAP-27 and -28, bovine indolicidin, as well as porcine PG-1 showed activity against many clinical isolates of fungi including those resistant to conventional medicines used in human therapy. All of those peptide caused the disruption of the fungi cell membrane [71]. Both human LL-37 and mouse mCRAMP cathelicidins showed similar pH-dependent activity against $C$. albicans at MIC between 15 and $20 \mu \mathrm{M}$ (the lower $\mathrm{pH}$ the higher growth inhibition of $C$. albicans). However, porcine PR-39 was shown to be inactive against fungi [99].

Some information about immunomodulatory activities of the cathelicidin-bovine indolicidin, was reported by Bowdish et al. [64]. According to their studies, indolicidin inhibits secretion of TNF-alpha from macrophages in response to LPS treatment and induces the production of the chemokine interleukin- 8 (IL8) in the human bronchial cell line. The other known biological function of cathelicidins is their influence on wound repair and angiogenesis, chemotaxis and antisepsis activity as well as induction of cytolysis, especially of the hematopoietic cell line and proliferating lymphocytes. Owing to inhibition of NADPH oxidase activity that generates reactive oxygen species, PR39 prevents tissue injury [77].

\section{Perspectives}

Intensive work on antimicrobial peptides is carried out all over the world in different scientific institutions as well as in pharmaceutical and biotechnological companies. Gene therapy through augmenting the level of cathelicidins was investigated but there has been little progress in this work [100, 101]. Currently, the possibility of applying the aerosolized protegrin directly into the lungs of patients with cystic fibrosis is being evaluated [102]. Up to $100 \%$ systemic protection against infections caused by intraperitoneal injection of $P$. aeruginosa, $S$. aureus and methicillin-resistant $S$. aureus was conferred in clinical tests in rats by PG-1 (pig peptide protegrin) [90]. Ovine cathelicidins SMAP29 and SMAP34 are probably candidates for use in human therapy against bacterial infection and immunocompromised persons. For example, SMAP 29 is highly effective against infections causing low hydratation of respiratory airway surface liquid during cystic fibrosis lung disease. The peptide was effective under both low and high $\mathrm{NaCl}$ concentration. Therefore, it can be used to design of an artificial salt tolerant peptide antibiotics [103]. The saltresistant, antimicrobial properties of CAP18 and SMAP29 suggest potential for the treatment of bacterial infections in 
individuals with cystic fibrosis, who have high levels of sodium chloride in the sweat $[103,104]$. The in vitro study on mouse bone marrow-derived dendritic cells as well as the in vivo study on cathelicidin-deficient mice, showed that local administration of synthetic human and murine cathelicidins inhibited the allergic response. All the above listed studies confirm the ability of synthetic cathelicidins to kill or to inhibit microbes. Thus, the therapeutic use of cathelicidins or modulators of their expression is to be considered [105].

Many reports about production and activity of synthetic antimicrobial peptides appear only in the patent literature. Researchers try to obtain peptides that are shorter than natural ones but with the same or even higher activity against microbes. [106, 107] For example, 12- to 14-aa peptides like bactenecin and indolicidin derivatives were shown to have excellent broad-spectrum antimicrobial activities [106]. Also the synthetic peptide Rev4, designed based on indolicidin, showed high antimicrobial activity and improved protease resistance, since this peptide also appeared a potent inhibitor of different types of proteases [108].

Different strategies for using AMPs are taken into account. One of them is the use of a single anti-infective agent. Another possibility is taking advantage of the synergistic or additive effects of antimicrobial peptides and conventional antibiotics, or exploiting their immunostimulatory effects. The use of AMPs as endotoxin-neutralizing agents is also predicted [109]. The main advantages of using antimicrobial peptides are their broad spectrum of activity and fast action. Probably, the AMPs will show a low level of induced resistance in pathogens. However, the high costs of their synthesis, screening and manufacturing, and also the natural resistance of pathogens are the main disadvantages. Moreover, the susceptibility to proteolysis, reduced activity in physiological salts, serum, and $\mathrm{pH}$ sensitivity, and confounding biological functions (e.g. angiogenesis) should be taken into account. Gene therapy aimed at increasing the expression of the antimicrobial peptides in a patient's tissues is other possible strategy which may be used. However, the fault of many viruses used as vectors in gene therapies is the potential possibility to cause inflammation. Increasing the expression of antimicrobial peptides by supplementing the diet with presumed regulators of their secretion seems to be the better option. The results of preliminary study on the influence of goat diet supplementation by yeast on expression of AMPs genes in milk somatic cells seem to indicate a positive influence of such supplementation on expression of one cathelicidin gene (Jarczak, personal communication). Nowadays, several peptides seem promising for possible drug development in preclinical studies [57, 109-112]. Despite the large amount of additional information about the cathelicidins in mammals, there are still limited information on their multiple functions. It is important to recognize novel epigenetic mechanisms that control the tissue-specific expression of the AMP genes, in order to develop novel therapeutic strategies intended to potentiate endogenous production of these molecules. To fully understand the functional potential of cathelicidins in livestock, we need to precisely understand their in vivo role. This role, however, is still unclear in domestic species.

Further studies are needed to determine the transcriptomic patterns of particular cathelicidins in particular time points of infection to unravel their role in disease. Furthermore, there is a need to develop mouse models where genes encoding AMPs are either knocked-down or overactive to see if AMPs can influence an animal's physiology and determine how these effects impact host physiology and pathology. Screening for epigenetic effects on gene expression that can be altered in such models is also required. Other animal models (goat, bovine) are also required.

Acknowledgments The study was supported by the Polish Ministry of Science and Higher Education within research Project no. N311 075339 and by IGAB Project No. S.IV.2.

Open Access This article is distributed under the terms of the Creative Commons Attribution License which permits any use, distribution, and reproduction in any medium, provided the original author(s) and the source are credited.

\section{References}

1. Bals R, Wilson JM (2003) Cathelicidins: a family of multifunctional antimicrobial peptides. Cell Mol Life Sci 60:711-720

2. Hultmark D, Steiner H, Rasmuson T, Boman HG (1980) Insect immunity. Purification and properties of three inducible bactericidal proteins from hemolymph of immunized pupae of Hyalophora cecropia. Eur J Biochem 106:7-16

3. Zasloff M (1987) Magainins, a class of antimicrobial peptides from Xenopus skin: isolation, characterization of two active forms, and partial cDNA sequence of a precursor. Proc Natl Acad Sci USA 84:5449-5453

4. Gennaro R, Skerlavaj B, Romeo D (1989) Purification, composition, and activity of two bactenecins, antibacterial peptides of bovine neutrophils. Infect Immun 5:3142-3146

5. Lee JY, Boman A, Sun CX, Andersson M, Jörnvall H, Mutt V, Boman HG (1989) Antibacterial peptides from pig intestine: isolation of a mammalian cecropin. Proc Natl Acad Sci USA 86:9159-9162

6. Hirata M, Yoshida M, Inada K, Kirikae T (1990) Investigation of endotoxin binding cationic proteins from granulocytes; agglutination of erythrocytes sensitized with Re-LPS. Adv Exp Med Biol 256:287-299

7. Das H, Sharma B, Kumar A (2006) Cloning and characterization of novel cathelicidin cDNA sequence of Bubalus bubalis homologous to Bos taurus cathelicidin-4. DNA Seq 17:407-414

8. Scocchi M, Bontempo D, Boscolo S, Tomasinsig L, Giulotto E, Zanetti M (1999) Novel cathelicidins in horse leukocytes (1). FEBS Lett 457:459-464 
9. Kokryakov VN, Harwig SS, Panyutich EA, Shevchenko AA, Aleshina GM, Shamova OV, Korneva HA, Lehrer RI (1993) Protegrins: leukocyte antimicrobial peptides that combine features of corticostatic defensins and tachyplesins. FEBS Lett 327:231-236

10. Brogden KA, Klafa VC, Ackermann MR, Palmquist DE, McCray PB Jr, Tack BF (2001) The ovine cathelicidin SMAP29 kills ovine respiratory pathogens in vitro and in an ovine model of pulmonary infection. Antimicrob Agents Chemother 45:331-334

11. Shamova O, Brogden KA, Zhao C, Nguyen T, Kokryakov VN, Lehrer RI (1999) Purification and properties of proline-rich antimicrobial peptides from sheep and goat leukocytes. Infect Immun 67:4106-4111

12. Fernández de Mera IG, Pérez de la Lastra JM, Ayoubi P, Naranjo V, Kocan KM, Gortazar C, de la Fuente J (2008) Differential expression of inflammatory and immune response genes in mesenteric lymph nodes of Iberian red deer (Cervus elaphus hispanicus) naturally infected with Mycobacterium bovis. Dev Comp Immunol 32:85-91

13. Xiao Y, Cai Y, Bommineni YR, Fernando SC, Prakash O, Gilliland SE, Zhang G (2006) Identification and functional characterization of three chicken cathelicidins with potent antimicrobial activity. J Biol Chem 281:2858-2867

14. Dürr UH, Sudheendra US, Ramamoorthy A (2006) LL-37, the only human member of the cathelicidin family of antimicrobial peptides. Biochim Biophys Acta 1758:1408-1425

15. Uzzell T, Stolzenberg ED, Shinnar AE, Zasloff M (2003) Hagfish intestinal antimicrobial peptides are ancient cathelicidins. Peptides 24:1655-1667

16. Zhao C, Nguyen T, Boo LM, Hong T, Espiritu C, Orlov D, Wang W, Waring A, Lehrer RI (2001) RL-37, an alpha-helical antimicrobial peptide of the rhesus monkey. Antimicrob Agents Chemother 45:2695-2702

17. Bals R, Lang C, Weiner DJ, Vogelmeier C, Welsch U, Wilson JM (2001) Rhesus monkey (Macaca mulatta) mucosal antimicrobial peptides are close homologues of human molecules. Clin Diagn Lab Immunol 8:370-375

18. Gallo RL, Kim KJ, Bernfield M, Kozak CA, Zanetti M, Merluzzi L, Gennaro R (1997) Identification of CRAMP, a cathelin-related antimicrobial peptide expressed in the embryonic and adult mouse. J Biol Chem 272:13088-13093

19. Termén S, Tollin M, Olsson B, Svenberg T, Agerberth B, Gudmundsson GH (2003) Phylogeny, processing and expression of the rat cathelicidin rCRAMP: a model for innate antimicrobial peptides. Cell Mol Life Sci 60:536-549

20. Nagaoka I, Tsutsumi-Ishii Y, Yomogida S, Yamashita T (1997) Isolation of cDNA encoding guinea pig neutrophil cationic antibacterial polypeptide of $11 \mathrm{kDa}$ (CAP11) and evaluation of CAP11 mRNA expression during neutrophil maturation. J Biol Chem 272:22742-22750

21. Wang Y, Hong J, Liu X, Yang H, Liu R, Wu J, Wang A, Lin D, Lai R (2008) Snake cathelicidin from Bungarus fasciatus is a potent peptide antibiotics. PLoS ONE 3:e3217. doi:10.1371/ journal.pone.0003217

22. Zanetti M, Gennaro R, Romeo D (1995) Cathelicidins: a novel protein family with a common proregion an a variable $\mathrm{C}$-terminal antimicrobial domain. FEBS Lett 374:1-5

23. Boman HG (1995) Peptide antibiotics and their role in innate immunity. Annu Rev Immunol 13:61-92

24. Zanetti M (2005) The role of cathelicidins in the innate host defenses of mammals. Curr Issues Mol Biol 7:179-196

25. Tomasinsig L, Zanetti M (2005) The cathelicidins-structure, function and evolution. Curr Protein Pept Sci 6:23-34

26. Di Nardo A, Vitiello A, Gallo RL (2003) Cutting edge: mast cell antimicrobial activity is mediated by expression of cathelicidin antimicrobial peptide. J Immunol 170:2274-2278
27. Nagaoka I, Hirota S, Niyonsaba F, Hirata M, Adachi Y, Tamura H, Tanaka S, Heumann D (2002) Augmentation of the lipopolysaccharide-neutralizing activities of human cathelicidin CAP18/LL-37-derived antimicrobial peptides by replacement with hydrophobic and cationic amino acid residues. Clin Diagn Lab Immunol 9:972-982

28. Zanetti M, Storici P, Tossi A, Scocchi M, Gennaro R (1994) Molecular cloning and chemical synthesis of a novel antibacterial peptide derived from pig myeloid cells. J Biol Chem 269:7855-7858

29. Storici P, Scocchi M, Tossi A, Gennaroc R, Zanettia M (1994) Chemical synthesis and biological activity of a novel antibacterial peptide deduced from a pig myeloid cDNA. FEBS Lett 337:303-307

30. Tossi A, Scocchi M, Zanetti M, Storici P, Gennaro R (1995) PMAP-37, a novel antibacterial peptide from pig myeloid cells. cDNA cloning, chemical synthesis and activity. Eur J Biochem 228:941-946

31. Gudmundsson GH, Magnusson KP, Chowdhary BP, Johansson M, Andersson L, Boman HG (1995) Structure of the gene for porcine peptide antibiotic PR-39, a cathelin gene family member: comparative mapping of the locus for the human peptide antibiotic FALL-39. Proc Natl Acad Sci USA 92:7085-7089

32. Lenarcic B, Ritonja A, Dolenc I, Stoka V, Berbic S, Pungercar J, Strukelj B, Turk V (1993) Pig leukocyte cysteine proteinase inhibitor (PLCPI), a new member of the stefin family. FEBS Lett 336:289-292

33. Strukelj B, Pungercar J, Kopitar G, Renko M, Lenarcic B, Berbić S, Turk V (1995) Molecular cloning and identification of a novel porcine cathelin-like antibacterial peptide precursor. Biol Chem Hoppe Seyler 376:507-510

34. Zhao C, Ganz T, Lehrer RI (1995) Structures of genes for two cathelin-associated antimicrobial peptides: prophenin-2 and PR39. FEBS Lett 376:130-134

35. Fahrner RL, Dieckmann T, Harwig SS, Lehrer RI, Eisenberg D, Feigon J (1996) Solution structure of protegrin-1, a broadspectrum antimicrobial peptide from porcine leukocytes. Chem Biol 3:543-550

36. Scocchi M, Wang S, Zanetti M (1997) Structural organization of the bovine cathelicidin gene family and identification of a novel member. FEBS Lett 417:311-315

37. Storici P, Tossi A, Lenarcic B, Romeo D (1996) Purification and structural characterization of bovine cathelicidins, precursors of antimicrobial peptides. Eur J Biochem 238:769-776

38. Selsted ME, Novotny MJ, Morris WL, Tang YQ, Smith W, Cullor JS (1992) Indolicidin, a novel bactericidal tridecapeptide amide from neutrophils. J Biol Chem 267:4292-4295

39. Skerlavaj B, Gennaro R, Bagella L, Merluzzi L, Risso A, Zanetti M (1996) Biological characterization of two novel cathelicidinderived peptides and identification of structural requirements for their antimicrobial and cell lytic activities. J Biol Chem 271: 28375-28381

40. Huttner KM, Lambeth MR, Burkin HR, Burkin DJ, Broad TE (1998) Localization and genomic organization of sheep antimicrobial peptide genes. Gene 206:85-91

41. Mahoney MM, Lee AY, Brezinski-Caliguri DJ, Huttner KM (1995) Molecular analysis of the sheep cathelin family reveals a novel antimicrobial peptide. FEBS Lett 377:519-522

42. Bagella L, Scocchi M, Zanetti M (1995) cDNA sequences of three sheep myeloid cathelicidins. FEBS Lett 376:225-228

43. Anderson RC, Hancock RE, Yu PL (2004) Antimicrobial activity and bacterial-membrane interaction of ovine-derived cathelicidins. Antimicrob Agents Chemother 48:673-676

44. Chang CI, Zhang YA, Zou J, Nie P, Secombes CJ (2006) Two cathelicidin genes are present in both rainbow trout 
(Oncorhynchus mykiss) and atlantic salmon (Salmo salar). Antimicrob Agents Chemother 50:185-195

45. Treffers C, Chen L, Anderson RC, Yu PL (2005) Isolation and characterisation of antimicrobial peptides from deer neutrophils. Int J Antimicrob Agents 26:165-169

46. Tossi A, Sandri L, Giangaspero A (2000) Amphipathic, alphahelical antimicrobial peptides. Biopolymers 55:4-30

47. Harwig SS, Kokryakov VN, Swiderek KM, Aleshina GM, Zhao C, Lehrer RI (1995) Prophenin-1, an exceptionally proline-rich antimicrobial peptide from porcine leukocytes. FEBS Lett 362:65-69

48. Van Dijk A, Veldhuizen EJ, van Asten AJ, Haagsman HP (2005) CMAP27, a novel chicken cathelicidin-like antimicrobial protein. Vet Immunol Immunopathol 106:321-327

49. Goitsuka R, Chen CL, Benyon L, Asano Y, Kitamura D, Cooper MD (2007) Chicken cathelicidin-B1, an antimicrobial guardian at the mucosal $\mathrm{M}$ cell gateway. Proc Natl Acad Sci USA 104:15063-15068

50. Hirata M, Shimomura Y, Yoshida M, Morgan JG, Palings I, Wilson D, Yen MH, Wright SC, Larrick JW (1994) Characterization of a rabbit cationic protein (CAP18) with lipopolysaccharide-inhibitory activity. Infect Immun 62:1421-1426

51. Ooi CE, Weiss J, Levy O, Elsbach P (1990) Isolation of two isoforms of a novel 15-kDa protein from rabbit polymorphonuclear leukocytes that modulate the antibacterial actions of other leukocyte proteins. J Biol Chem 265:15956-15962

52. Sanchez JF, Hoh F, Strub MP, Aumelas A, Dumas C (2002) Structure of the cathelicidin motif of protegrin-3 precursor: structural insights into the activation mechanism of an antimicrobial protein. Structure 10:1363-1370

53. Zhao C, Liu L, Lehrer RI (1994) Identification of a new member of the protegrin family by cDNA cloning. FEBS Lett 346:285-288

54. Zhao C, Ganz T, Lehrer RI (1995) The structure of porcine protegrin genes. FEBS Lett 368:197-202

55. Zaiou M, Gallo RL (2002) Cathelicidins, essential gene-encoded mammalian antibiotics. J Mol Med 80:549-561

56. Zanetti M (2004) Cathelicidins, multifunctional peptides of the innate immunity. J Leukoc Biol 75:39-48

57. Bagnicka E, Strzałkowska N, Jóźwik A, Krzyżewski J, Horbańczuk J, Zwierzchowski L (2010) Expression and polymorphism of defensins in farm animals. Acta Biochim Pol 57:487-497

58. Schneider JJ, Unholzer A, Schaller M, Schäfer-Korting M, Korting HC (2005) Human defensins. J Mol Med 83:587-595

59. Bals R, Wang X, Zasloff M, Wilson JM (1998) The peptide antibiotic LL-37/hCAP-18 is expressed in epithelia of the human lung where it has broad antimicrobial activity at the airway surface. Proc Natl Acad Sci USA 95:9541-9546

60. Frohm A, Agerberth B, Ahangari G, Stahle-Backdahl M, Linden S, Wigzell H, Gudmundsson GH (1997) The expression of the gene coding for the antibacterial peptide LL-37 is induced in human keratinocytes during inflammatory disorders. J Biol Chem 272:15258-15263

61. Rivas-Santiago B, Hernandez-Pando R, Carranza C, Juarez E, Contreras JL, Aguilar-Leon D, Torres M, Sada E (2008) Expression of cathelicidin LL-37 during Mycobacterium tuberculosis infection in human alveolar macrophages, monocytes, neutrophils, and epithelial cells. Infect Immun 76:935-941

62. Zasloff M (2007) Antimicrobial peptides, innate immunity, and the normally sterile urinary tract. J Am Soc Nephrol 18:2810 2816

63. Bals R (2000) Epithelial antimicrobial peptides in host defense against infection. Respir Res 1:141-150

64. Bowdish DM, Davidson DJ, Scott MG, Hancock RE (2005) Immunomodulatory activities of small host defense peptides. Antimicrob Agents Chemother 49:1727-1732
65. Tomasinsig L, De Conti G, Skerlavaj B, Piccinini R, Mazzilli M, D'Este F, Tossi A, Zanetti M (2010) Broad-spectrum activity against bacterial mastitis pathogens and activation of mammary epithelial cells support a protective role of neutrophil cathelicidins in bovine mastitis. Infect Immun 78:1781-1788

66. Lee JY, Yang ST, Kim HJ, Lee SK, Jung HH, Shin SY, Kim JI (2009) Different modes of antibiotic action of homodimeric and monomeric bactenecin, a cathelicidin-derived antibacterial peptide. BMB Rep 42:586-592

67. Zanetti M, Del Sal G, Storici P, Schneider C, Romeo D (1993) The cDNA of the neutrophil antibiotic Bac5 predicts a prosequence homologous to a cysteine proteinase inhibitor that is common to other neutrophil antibiotic. J Biol Chem 268:522526

68. Risso A, Zanetti M, Gennaro R (1998) Cytotoxicity and apoptosis mediated by two peptides of innate immunity. Cell Immunol 189:107-115

69. Risso A, Braidot E, Sordano MC, Vianello A, Macrì F, Skerlavaj B, Zanetti M, Gennaro R, Bernardi P (2002) BMAP-28, an antibiotic peptide of innate immunity, induces cell death through opening of the mitochondrial permeability transition pore. Mol Cell Biol 22:1926-1935

70. Del Sal G, Storici P, Schneider C, Romeo D, Zanetti M (1992) cDNA cloning of the neutrophil bactericidal peptide indolicidin. Biochem Biophys Res Commun 187:467-472

71. Benincasa M, Scocchi M, Pacor S, Tossi A, Nobili D, Basaglia G, Busetti M, Gennaro R (2006) Fungicidal activity of five cathelicidin peptides against clinically isolated yeasts. J Antimicrob Chemother 58:950-959

72. Selsted ME, Ouellette AJ (2005) Mammalian defensins in the antimicrobial immune response. Nat Immunol 6:551-557

73. Bera A, Singh S, Nagaraj R, Vaidya T (2003) Induction of autophagic cell death in Leishmania donovani by antimicrobial peptides. Mol Biochem Parasitol 127:23-35

74. Aley SB, Zimmerman M, Hetsko M, Selsted ME, Gillin FD (1994) Killing of Giardia lamblia by cryptdins and cationic neutrophil peptides. Infect Immun 62:5397-5403

75. Jang H, Ma B, Nussinov R (2007) Conformational study of the protegrin-1 (PG-1) dimer interaction with lipid bilayers and its effect. BMC Struct Biol 2:7-21

76. Yasin B, Harwig SS, Lehrer RI, Wagar EA (1996) Susceptibility of Chlamydia trachomatis to protegrins and defensins. Infect Immun 64:709-713

77. Ramanathan B, Davis EG, Ross CR, Blecha F (2002) Cathelicidins: microbicidal activity, mechanisms of action, and roles in innate immunity. Microbes Infect 4:361-372

78. Miyasaki KT, Iofel R, Lehrer RI (1997) Sensitivity of periodontal pathogens to the bactericidal activity of synthetic protegrins, antibiotic peptides derived from porcine leukocytes. J Dent Res 76:1453-1459

79. Boman HG, Agerberth B, Boman A (1993) Mechanisms of action on Escherichia coli of cecropin P1 and PR-39, two antibacterial peptides from pig intestine. Infect Immun 61:2978-2984

80. Wu H, Zhang G, Minton JE, Ross CR, Blecha F (2000) Regulation of cathelicidin gene expression: induction by lipopolysaccharide, interleukin-6, retinoic acid, and Salmonella enterica serovar typhimurium infection. Infect Immun 68:5552-5558

81. Ramanathan B, Minton JE, Ross CR, Blecha F (2005) PU.1-mediated transcriptional regulation of prophenin-2 in primary bone marrow cells. Gene 352:1-9

82. Shamova O, Orlov D, Stegemann C, Czihal P, Hoffmann R, Brogden K, Kolodkin N, Sakuta G, Tossi A, Sahl HG, Kokryakov V, Lehrer RI (2009) ChBac3.4: a novel proline-rich antimicrobial peptide from goat leukocytes. Int J Pept Res Ther $15: 31-42$ 
83. Mukhopadhyaya CS, Kumar R, Brahc GS (2010) Gallinacin and fowlicidin: two promising antimicrobial peptides in chickens: a review. Vet World 3:297-300

84. Zhao C, Nguyen T, Liu L, Sacco RE, Brogden KA, Lehrer RI (2001) Gallinacin-3, an inducible epithelial beta-defensin in the chicken. Infect Immun 69:2684-2691

85. Skerlavaj B, Scocchi M, Gennaro R, Risso A, Zanetti M (2001) Structural and functional analysis of horse cathelicidin peptides. Antimicrob Agents Chemother 45:715-722

86. Maier VH, Dorn KV, Gudmundsdottir BK, Gudmundsson GH (2008) Characterisation of cathelicidin gene family members in divergent fish species. Mol Immunol 45:3723-3730

87. Anderson RC, Yu PL (2003) Isolation and characterisation of proline/arginine-rich cathelicidin peptides from ovine neutrophils. Biochem Biophys Res Commun 312:1139-1146

88. Andreu D, Rivas L (1998) Animal antimicrobial peptides: an overview. Biopolymers 47:415-433

89. White SH, Wimley WC, Selsted ME (1995) Structure, function, and membrane integration of defensins. Curr Opin Struct Biol $5: 521-527$

90. Reddy KV, Yedery RD, Aranha C (2004) Antimicrobial peptides: premises and promises. Int $\mathrm{J}$ Atimicrob Agents 24:536-547

91. Hancock RE, Diamond G (2000) The role of cationic antimicrobial peptides in innate host defences. Trends Microb 8:402-410

92. Brogden KA (2005) Antimicrobial peptides: pore formers or metabolic inhibitors in bacteria? Nat Rev Microbiol 3:238-250

93. Wiechuła BE, Tustanowski JP, Martirosian G (2006) Peptydy antydrobnoustrojowe. Wiad Lek 59:542-547

94. Seil M, Nagant C, Dehaye JP, Vandenbranden M, Lensink MF (2010) Spotlight on human LL-37, an immunomodulatory peptide with promising cell-penetrating properties. Pharmaceuticals 3:3435-3460

95. Lee DG, Kim HK, Kim SA, Park Y, Park SC, Jang SH, Hahm KS (2003) Fungicidal effect of indolicidin and its interaction with phospholipid membranes. Biochem Biophys Res Commun 305:305-310

96. Hsu CH, Chen C, Jou ML, Lee AY, Lin YC, Yu YP, Huang WT, $\mathrm{Wu}$ SH (2005) Structural and DNA-binding studies on the bovine antimicrobial peptide, indolicidin: evidence for multiple conformations involved in binding to membranes and DNA. Nucleic Acids Res 33:4053-4064

97. Marchand C, Krajewski K, Lee HF, Antony S, Johnson AA, Amin R, Roller P, Kvaratskhelia M, Pommier Y (2006) Covalent binding of the natural antimicrobial peptide indolicidin to DNA abasic sites. Nucleic Acids Res 34:5157-5165
98. Bowdish DM, Davidson DJ, Hancock RE (2006) Immunomodulatory properties of defensins and cathelicidins. Curr Top Microbiol Immunol 306:27-66

99. López-García B, Lee PH, Yamasaki K, Gallo RL (2005) Antifungal activity of cathelicidins and their potential role in Candida albicans skin infection. J Invest Dermatol 125:108-115

100. Bals R, Weiner DJ, Meegalla RL, Wilson JM (1999) Transfer of a cathelicidin peptide antibiotic gene restores bacterial killing in a cystic fibrosis xenograft model. J Clin Invest 103:1113-1117

101. Rogan MP, Gerghty P, Greene CM, O’Neill SJ, Taggart CC, McElvaney NG (2006) Antimicrobial proteins and polypeptides in pulmonary innate defence. Respir Res 17:7-29

102. Levy O (2000) Antimicrobial proteins and peptides of blood: templates for novel antimicrobial agents. Blood 96:2664-2672

103. Travis SM, Anderson NN, Forsyth WR, Espiritu C, Conway BD, Greenberg EP, McCray PB Jr, Lehrer RI, Welsh MJ, Tack BF (2000) Bactericidal activity of mammalian cathelicidin-derived peptides. Infect Immun 68:2748-2755

104. Brown MB, McCarty NA, Millard-Stafford M (2011) Highsweat $\mathrm{Na}+$ in cystic fibrosis and healthy individuals does not diminish thirst during exercise in the heat. Am J Physiol Regul Integr Comp Physiol 301:1177-1185

105. Di Nardo A, Braff MH, Taylor KR, Na C, Granstein RD, McInturff JE, Krutzik S, Modlin RL, Gallo RL (2007) Cathelicidin antimicrobial peptides block dendritic cell TLR4 activation and allergic contact sensitization. $\mathbf{J}$ Immunol 178:1829-1834

106. Hancock REW, Chapple DS (1999) Peptide antibiotics. Minireview. Antimicrob Agents Chemother 43:1317-1323

107. Kondejewski LH, Farmer SW, Wishart DS, Hancock RE, Hodges RS (1996) Gramicidin S is active against both grampositive and gram-negative bacteria. Int $\mathrm{J}$ Pept Protein Res 47:460-466

108. Li Q, Lawrence CB, Maelor Davies H, Everett NP (2002) A tridecapeptide possesses both antimicrobial and protease-inhibitory activities. Peptides 23:1-6

109. Gordon YJ, Romanowski EG, McMermott AM (2005) A review of antimicrobial peptides and their therapeutic potential as antiinfective drugs. Curr Eye Res 30:505-515

110. Koczulla AR, Bals R (2003) Antimicrobial peptides: current status and therapeutic potential. Drugs 63:389-406

111. Meyerholz DK, Ackermann MR (2005) Antimicrobial peptides and sufactant proteins in ruminant respiratory tract disease. Vet Immunol Immunopathol 107:91-96

112. Sherman H, Chapnik N, Froy O (2006) Albumin and amino acids upregulate the expression of human beta-defensin 1 . Mol Immunol 43:1617-1623 